\title{
Remote Central-to-Axial Chirality Conversion: Direct Atroposelective Ester to Biaryl Transformation
}

\author{
Achim Link and Christof Sparr*
}

\section{Dedicated to Professor Andreas Pfaltz on the occasion of his 70th birthday}

\begin{abstract}
A strategy for the remote central-to-axial chirality conversion by simultaneous planarization of an encoding and a transient stereocenter is presented. Based on a diastereoselective double addition of a chiral 1,5-bifunctional organomagnesium alkoxide reagent to a broad range of aryl ester substrates, axially chiral biaryls are directly obtained upon in situ reduction. Various structurally distinct atropisomeric biaryl silanes that serve as valuable chiral biaryl anion surrogates are accessible in one step with e.r. values of up to 98:2.
\end{abstract}

Unique molecular topology is regularly characterized by chirality elements of a different nature. However, the realms of stereochemical diversity are unmet by current synthetic methodology that controls their configuration. While stereocenter configuration is governed by numerous seminal methods, stereocontrol over other chirality elements is often limited. The selective interconversion of compounds with different chirality elements is thus fundamental to advance stereochemistry. ${ }^{[1]}$

Rooted in the findings on external stereocontrol over stereogenic axes using chiral auxiliaries, ${ }^{[2]}$ several innovative approaches for the conversion of central to axial chirality were established by virtue of planarization of a proximal stereocenter (Scheme 1a). ${ }^{[3]}$ While these methods reliably provide atropisomers with high levels of stereospecificity, the steric bulk of the ortho substituents required for configurational stability of atropisomers hampers the accessibility of the substrates in enantiomerically enriched form. A remote central-to-axial chirality conversion would therefore be of particular value to render these strategies generally applicable. ${ }^{[4]}$

We thus considered a stereochemical relay by 1,4 -stereoinduction of an encoding to a proximal stereocenter, which controls the chirality conversion by the simultaneous planarization of both stereocenters. In particular, we envisaged an atroposelective one-step synthesis of biaryls from simple aryl esters (1) with a chiral 1,5-bifunctional ${ }^{[5]}$ organomagnesium alkoxide reagent $(\mathbf{3}$; Scheme $1 \mathrm{~b})$. The coupling of the ester with $\mathbf{3}$, prepared by deprotonation and double halogen-metal

[*] A. Link, Prof. Dr. C. Sparr

Department of Chemistry, University of Basel

St. Johanns-Ring 19, 4056 Basel (Switzerland)

E-mail: christof.sparr@unibas.ch

Homepage: http://www.chemie.unibas.ch/ sparr

(2) Supporting information and the ORCID identification number(s) for

(D) the author(s) of this article can be found under:

https://doi.org/10.1002/anie.201803472.

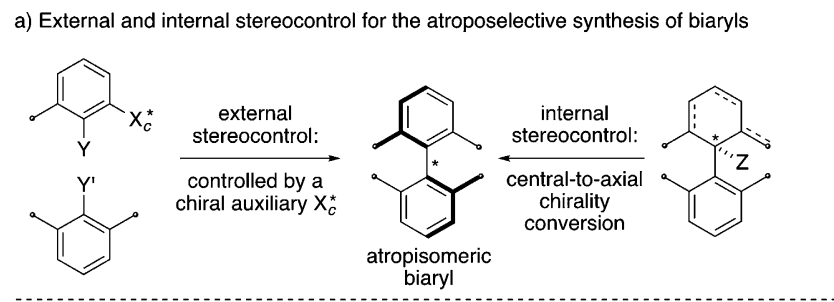

b) Remote internal stereocontrol: atroposelective ester to biaryl transformation (this work)

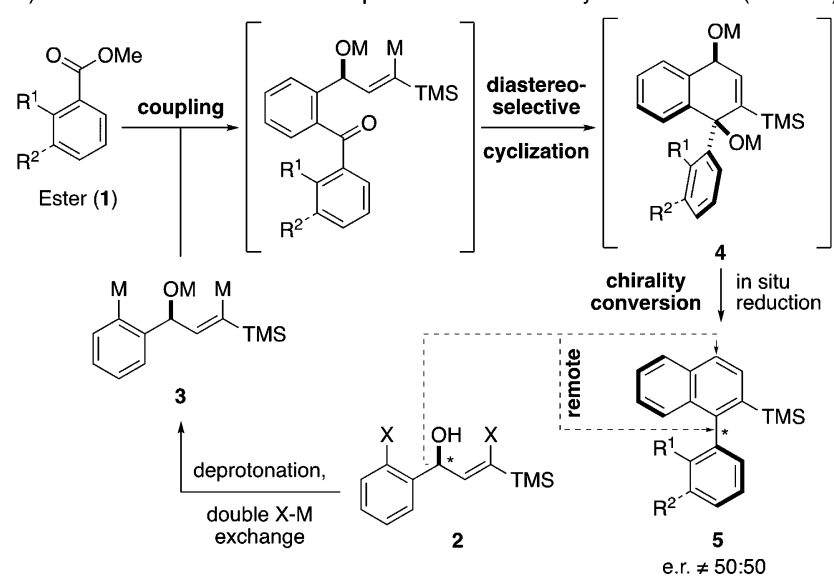

Scheme 1. a) Strategies for the atroposelective biaryl synthesis by either external or internal stereocontrol. ${ }^{[2,3]}$ b) Remote internal stereocontrol in the direct atroposelective transformation of esters into biaryls: coupling of the ester (1) with a chiral 1,5-bifunctional magnesium alkoxide reagent (3) triggers a diastereoselective cyclization controlling the configuration of a transient stereocenter in 4 . Upon in situ reduction, a central-to-axial chirality conversion leads to the atroposelective formation of biaryls by simultaneous planarization of the encoding and transient stereocenters. $M=$ metal, TMS = trimethylsilyl.

(X-M) exchange from the readily accessible precursor $\mathbf{2}$, would induce a diastereoselective cyclization ${ }^{[6]}$ and provide the bisalkoxide 4, which upon in situ reduction directly delivers enantioenriched axially chiral biaryls (5). Fascinated by the possibility to convert ortho-substituted aryl esters directly into various atropisomeric biaryls in enantioenriched form, we chose to study a silyl-stabilized reagent that would allow a versatile subsequent functionalization of the chiral biaryl silane products $\mathbf{5}$ at the ortho position.

The assets of the stereochemical relay of a remote to a transient stereocenter were instantly perceived by the simplicity and scalability of the synthesis of $(S)-\mathbf{2}$ in enantioenriched form (Scheme 2). Embracing stereoselective transfer hydrogenation or the Midland reduction, ${ }^{[7]}$ several stereoselective methods for the reduction of the 2-bromo- 


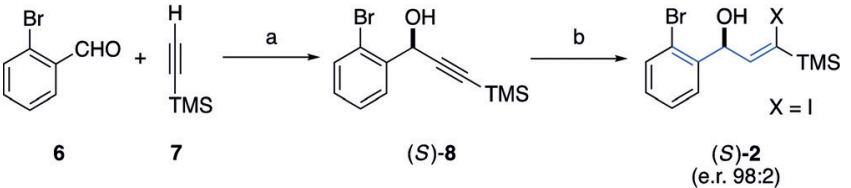

Scheme 2. Synthesis of (S)-2: a) 1. 7, iPrMgCl, THF, then 6, RT; 2. $\mathrm{MnO}_{2}$, EtOAc, $75^{\circ} \mathrm{C} ; 3$. (R)-Alpine-Borane, neat, $\mathrm{RT} ; 91 \%$ yield over three steps, e.r. $98: 2$; b) $i \mathrm{PrMgCl}$, Red-Al, THF, $0{ }^{\circ} \mathrm{C}$, then $-35^{\circ} \mathrm{C}$, EtOAc, $\mathrm{I}_{2}, 77 \%$ yield. THF = tetrahydrofuran, $\mathrm{TMS}=$ trimethylsilyl.

benzaldehyde-derived aryl alkynyl ketone provided the chiral propargylic alcohol $(S)-\mathbf{8}$ with an e.r. of 98:2 in $91 \%$ yield over three steps. A subsequent trans-selective hydroalumination with Red-Al $(E / Z>1: 99)^{[8]}$ and ensuing addition of iodine gave the chiral precursor $(S)-\mathbf{2}$ in $77 \%$ yield, with an e.r. value of $98: 2$, on a $45 \mathrm{mmol}$ scale.

With $(S)-2$ in hand, we investigated the double $\mathrm{X}-\mathrm{M}$ exchange of the corresponding alkoxide by a deprotonation/ magnesiation sequence. ${ }^{[9]}$ Initially, the addition to a mixture of $i \mathrm{PrMgCl}$ in a slurry of fine magnesium powder in THF only afforded mono-metalation at the alkenyl position (Table 1, entry 1). We therefore activated the magnesium with $\mathrm{LiCl}$ at $40^{\circ} \mathrm{C}^{[10]}$ to reach full metalation within 45 minutes in THF, $\mathrm{Et}_{2} \mathrm{O}$, or 2-MTHF (entries 2-5). These solutions of stable $(S)$-3 were directly used to convert methyl 1-naphthoate (1a; $1 \mathrm{~h}$ at RT) into the intermediary 1,4 -bisalkoxide $4 .{ }^{[11]}$ We next investigated the in situ reduction by adding $\mathrm{Ti}(\mathrm{O} i \mathrm{Pr})_{4}$, which formed a black slurry with the residual elemental magnesium, thus indicating the formation of low-valent titanium species. ${ }^{[12]}$ Gratifyingly, the formation of the desired product was observed in $\mathrm{Et}_{2} \mathrm{O}$ and the axially chiral biaryl $\left(R_{a}\right)-\mathbf{5}$ a was isolated in $16 \%$ yield with an excellent e.r. value of 98:2

Table 1: Optimization of the atroposelective ester to biaryl transformation with remote central-to-axial chirality conversion.
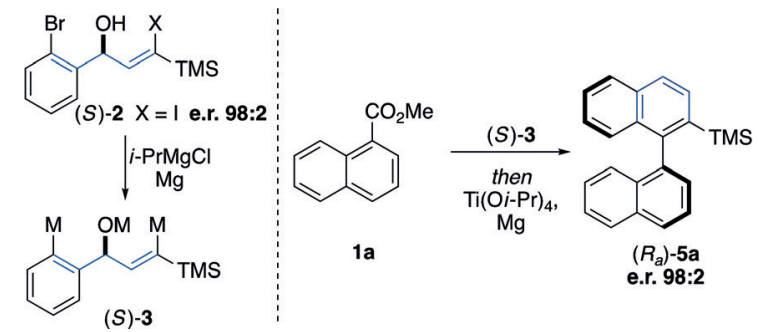

\begin{tabular}{|c|c|c|c|c|}
\hline Entry & Metalation $^{[\mathrm{a}]}$ & Addition $^{[b]}$ & Reduction $^{[c]}$ & Yield $[\%]^{[d}$ \\
\hline 1 & $\mathrm{THF}, \mathrm{RT}^{[\mathrm{e}]}$ & - & - & - \\
\hline 2 & $\mathrm{THF}, \mathrm{LiCl}, 40^{\circ} \mathrm{C}$ & 1.50 equiv 3 & THF, RT & - \\
\hline 3 & $\mathrm{Et}_{2} \mathrm{O}, \mathrm{LiCl}, 40^{\circ} \mathrm{C}$ & 1.50 equiv 3 & $\mathrm{Et}_{2} \mathrm{O}, \mathrm{RT}$ & $16^{[\mathrm{f}]}$ \\
\hline 4 & 2-MTHF, $\mathrm{LiCl}, 40^{\circ} \mathrm{C}$ & 1.50 equiv 3 & 2-MTHF, RT & - \\
\hline 5 & MTBE, $\mathrm{LiCl}, 40^{\circ} \mathrm{C}^{[\mathrm{e}]}$ & 1.50 equiv 3 & - & - \\
\hline 6 & $\mathrm{Et}_{2} \mathrm{O}, \mathrm{LiCl}, 40^{\circ} \mathrm{C}$ & 1.50 equiv 3 & THF, RT & $80^{[f]}$ \\
\hline 7 & $\mathrm{Et}_{2} \mathrm{O}, \mathrm{LiCl}, 40^{\circ} \mathrm{C}$ & 1.25 equiv 3 & THF, RT & $82^{[f]}$ \\
\hline 8 & $\mathrm{Et}_{2} \mathrm{O}, \mathrm{LiCl}, 40^{\circ} \mathrm{C}$ & 1.10 equiv 3 & THF, RT & 79 \\
\hline 9 & $\mathrm{Et}_{2} \mathrm{O}, \mathrm{LiCl}, \mathrm{RT}$ & 1.10 equiv 3 & THF, RT & 58 \\
\hline 10 & $\mathrm{Et}_{2} \mathrm{O}, \mathrm{LiCl}, 40^{\circ} \mathrm{C}$ & 1.10 equiv $3^{[\mathrm{g}]}$ & $\mathrm{THF}, 40^{\circ} \mathrm{C}$ & 73 \\
\hline
\end{tabular}

[a] Mg powder $(3.00 \mathrm{mmol}), \mathrm{LiCl}(640 \mu \mathrm{mol}), i \mathrm{PrMgCl}(220-300 \mu \mathrm{mol})$ and (S)-2 (220-300 $\mu \mathrm{mol})$ in $4.0 \mathrm{~mL}$ solvent for $45 \mathrm{~min}$. [b] 1 a $(200 \mu \mathrm{mol})$ in the identical solvent $(2.0 \mathrm{~mL})$ at RT for $1 \mathrm{~h}$. [c] Specified solvent $(4.0 \mathrm{~mL})$ and $\mathrm{Ti}(\mathrm{O}-\mathrm{Pr})_{4}(600 \mu \mathrm{mol})$ for $1 \mathrm{~h}$ at RT. [d] Yield of the isolated product. [e] Incomplete metalation. [f] An e.r. of 98:2 was determined by HPLC. Conversion percentage $(c p)=100 .^{[13]}[\mathrm{g}]$ At $40^{\circ} \mathrm{C}$. [conversion percentage $(c p)=100] .{ }^{[13]}$ Considering that the heterogeneous nature of the reaction mixture retards the reduction step, a solvent mixture with THF was evaluated, which ultimately delivered the product in high yield $(80 \%$; entry 6). We next determined that 1.25 equivalents of $(S)-3$ are required as an optimal amount of reagent, thus providing $82 \%$ of the binaphthyl product $\left(R_{a}\right)-\mathbf{5} \mathbf{a}$ (entry 7$)$. Variation of the reaction conditions with 1.1 equivalents of $(S)$-2 indicated that the yield is only slightly compromised and that metalation at room temperature, or performing the entire reaction sequence at $40^{\circ} \mathrm{C}$, leads to lower overall efficiency $(58 \%$ and $73 \%$; entries $8-10)$. The degree of the central-to-axial chirality transfer in the formation of $\left(R_{a}\right)$-5a was not affected by changing the solvent and an excellent stereoselectivity was observed in all cases (entries 3, 6, and 7; $(c p)=100$ ).

Having defined an optimal reaction protocol, we next tested the scalability and the scope of the atroposelective ester to biaryl transformation. With a tenfold increase of the reaction scale, a similar yield and equal selectivity was observed for the formation of $\left(R_{a}\right)$-5a $(2.00 \mathrm{mmol}$; Table 2 , the absolute configuration of the product was assigned by X-ray crystallographic analysis). ${ }^{[14]}$ We then explored the substrate scope by examining various ortho-substituted benzoic acid esters. Methyl $o$-toluate was converted with similar efficiency and selectivity after increasing the reduction time to 3 hours $\left[\left(R_{a}\right)-\mathbf{5} \mathbf{b}\right]$, and also the annulated tetralin ester and $9 H$-fluorene ester were transformed with nearly complete stereoselectivity $\left[\left(R_{a}\right)-\mathbf{5} \mathbf{c}\right.$ and $\left.\left(R_{a}\right)-5 \mathbf{d}\right]$. Even an ortho-arylated methyl benzoate gave the desired product $\left(R_{a}\right)-\mathbf{5 e}$ with an e.r. value of 97:3 $(c p=98)$. Because of the mild reaction conditions and short reaction times, we investigated the limitations of the configurational stability of the biaryl products with small ortho substituents. ${ }^{[11,15]}$ Methyl 2-chlorobenzoate and methyl-2-fluorobenzoate led to a $65 \%$ and $78 \%$ yield for the corresponding axially chiral biaryls $\left(R_{a}\right) \mathbf{- 5} \mathbf{f}$ and $\left(R_{a}\right)$-5 $\mathbf{g}$ with remarkable e.r. values of $98: 2$ and $87: 13$, respectively. A notably low rotational barrier was measured for $\left(R_{a}\right)-\mathbf{5} \mathbf{g}\left(\Delta G^{+}{ }_{333 \mathrm{~K}}=\right.$ $112 \mathrm{~kJ} \mathrm{~mol}^{-1}$ ), thus underlining the mild nature of the method as it stereoselectively provides products with reduced configurational stability. Having established the efficiency of the one-step transformation of esters into atropisomeric biaryls, we became interested by the possibility to expeditiously prepare an axially chiral phosphine in enantioenriched form. ${ }^{[16]}$ Interestingly, when methyl 2-(diphenylphosphino)benzoate was treated with $(S)-\mathbf{3}$, the desired monophosphine $\left(R_{a}\right)-\mathbf{5} \mathbf{h}$ was obtained in $63 \%$ yield with an e.r. value of 95:5. Furthermore, to investigate the atroposelective synthesis for non-biaryl atropisomers, ${ }^{[17]}$ we prepared the methylthiophene derivative $\left(S_{a}\right)$-5' $\mathbf{i}$, which was obtained in $80 \%$ yield. Despite the low rotational barrier of $\Delta G^{+}{ }_{333 \mathrm{~K}}=115 \mathrm{~kJ} \mathrm{~mol}^{-1}$, a high enantioenrichment (e.r. value of 92:8) was attained, thus validating the scope of the remote central-to-axial chirality conversion beyond atropisomeric biphenyls.

We next evaluated the transformation of a protic ester substrate after initial deprotonation. Notably, the anionic form of $1 H$-indole-ester $\mathbf{1} \mathbf{j}$ was selectively transformed into the corresponding biaryl with complete selectivity inversion, ${ }^{[6]}$ giving aryl indole $\left(S_{a}\right) \mathbf{- 5} \mathbf{j}$ with an e.r. value of 98:2 (Scheme 3, $70 \%,(c p)=100) .^{[14]}$ 
Table 2: Scope of the atroposelective transformation of esters into biaryls. ${ }^{[\mathrm{a}-\mathrm{e}]}$
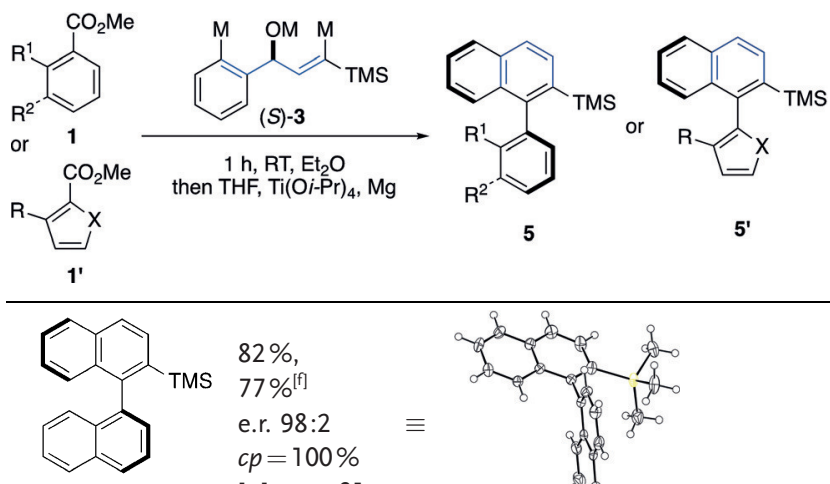

$82 \%$,

$77 \%[f]$

e.r. $98: 2$

$c p=100 \%$

$\left(R_{\mathrm{a}}\right)-5 \mathrm{a}$

$[\alpha]_{\mathrm{D}}=+81$

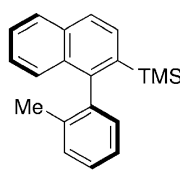

$80 \%[\mathrm{~g}]$

e.r. $98: 2$

$c p=100 \%$

$[\alpha]_{D}=+53$

$\left(R_{a}\right)-5 \mathrm{~b}$

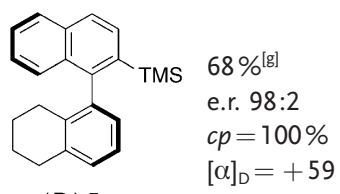

$\left(R_{a}\right)-5 \mathrm{c}$

$[\alpha]_{\mathrm{D}}=+59$

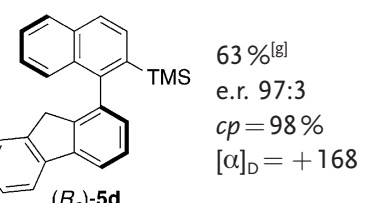

$\left(R_{a}\right)-5 \mathrm{~d}$

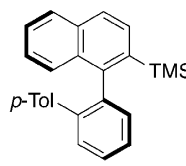

$57 \%[\mathrm{~g}]$

e.r. $97: 3$

$c p=98 \%$

$\left(R_{a}\right)-5$

$[\alpha]_{D}=+102$

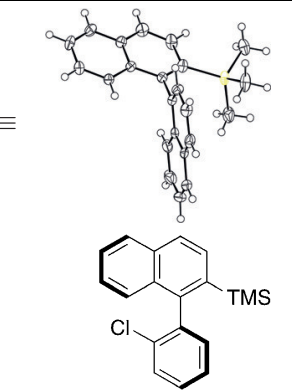

$65 \%$

e.r. $98: 2$

$c p=100 \%$

$[\alpha]_{D}=+63$

$\left(R_{a}\right)-5 f$

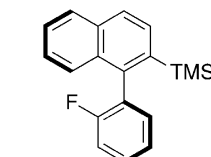

$78 \%[\mathrm{~g}]$

e.r. $87: 13$

$c p=77 \%$

$[\alpha]_{\mathrm{D}}=+10$

$\left(R_{a}\right)-5 \mathrm{~g}$
$G^{\ddagger}{ }_{333 \mathrm{~K}}=112 \mathrm{kJmol}^{-1}$

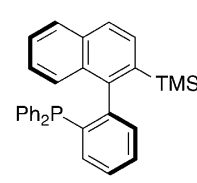

$\left(R_{a}\right)-5 \mathrm{~h}$

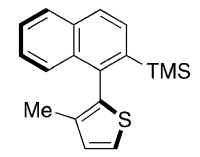

(S) -5 'i

$\Delta G^{\ddagger}{ }_{333 \mathrm{~K}}=115 \mathrm{kJmol}^{-1}$

$63 \%$

e.r. $95: 5$

$c p=94 \%$

$[\alpha]_{\mathrm{D}}=+71$

$80 \%$ [g]

e.r. $92: 8$

$c p=88 \%$

$[\alpha]_{D}=+11$

[a] Mg powder $(3.00 \mathrm{mmol}), \mathrm{LiCl}(640 \mu \mathrm{mol}), i \mathrm{PrMgCl}(250 \mu \mathrm{mol})$ and (S) $-2(250 \mu \mathrm{mol})$ in $2.0 \mathrm{~mL} \mathrm{Et} \mathrm{O}$ at $40^{\circ} \mathrm{C}$ for $45 \mathrm{~min}$. [b] 1 or $\mathbf{1}^{\prime}(200 \mu \mathrm{mol})$ in $\mathrm{Et}_{2} \mathrm{O}(4.0 \mathrm{~mL})$ at $\mathrm{RT}$ for $1 \mathrm{~h}$. [c] THF $(4.0 \mathrm{~mL})$ and $\mathrm{Ti}(\mathrm{OiPr})_{4}(600 \mu \mathrm{mol})$ for $1 \mathrm{~h}$ at RT. [d] Yield of isolated product is given. [e] Enantiomeric ratio determined by HPLC. [f] $2.00 \mathrm{mmol}$ scale. [g] Reduction with $\mathrm{Ti}(\mathrm{OiPr})_{4} /$ $\mathrm{Mg}$ for $3 \mathrm{~h}$.

To gain insight into the mechanism and the reactivity of the chiral 1,5-bifunctional organomagnesium alkoxide reagent, $(S)$-3 was treated with an equimolar amount of benzophenone, thus showing a higher reactivity at the aryl over the vinylsilane position (Scheme 4). Moreover, an excellent level of diastereoselectivity ${ }^{[6]}$ for the cis-diol $(S, S)$ $\mathbf{1 0}$ was confirmed by hydrolysis of $\mathbf{4}^{[11]}$ while the naphthyl endo conformation observed in the solid state emphasizes the preorganization of the precursor poised for a stereoselective arene formation. ${ }^{[14]}$

To assess the synthetic utility of the axially chiral biaryl silanes, ${ }^{[18]}\left(R_{a}\right)$-5a was treated with NBS and ICl to straightforwardly provide the analogous bromide $\left(R_{a}\right)$-11 and iodide $\left(R_{a}\right)$-12 (Scheme 5) ${ }^{[19]}$ Furthermore, a versatile diversification

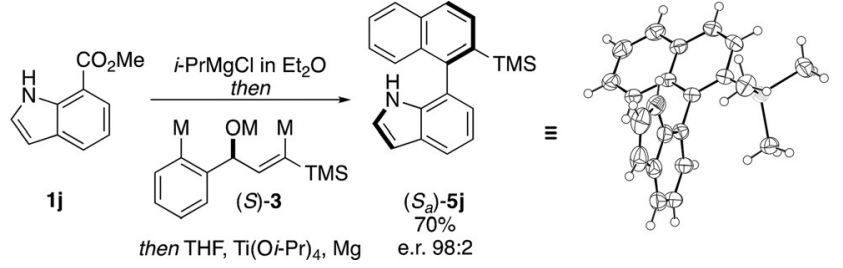

Scheme 3. Inversion of selectivity with the protic substrate $\mathbf{1 j}$. Double addition for $1 \mathrm{~h}$ at $\mathrm{RT}$, reduction for $3 \mathrm{~h}$ at $\mathrm{RT}, c p=100,[\alpha]_{\mathrm{D}}=-42 .{ }^{[14]}$.

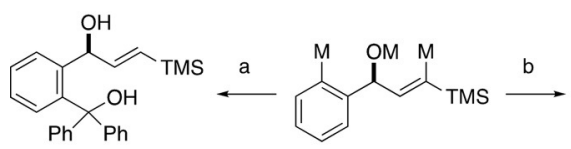

$(S)-9$

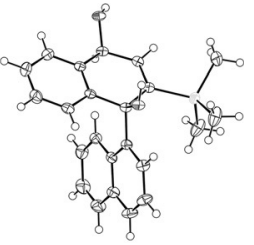

$(S, S)-10$

Scheme 4. Reactivity of (S)-3 and diastereoselectivity of the cyclization step. a) (S)-3, $\mathrm{Ph}_{2} \mathrm{CO}, \mathrm{Et}_{2} \mathrm{O},-78^{\circ} \mathrm{C}$ to $\mathrm{RT}, 65 \%$; b) (S)-3, methyl 1-naphthoate, $\mathrm{Et}_{2} \mathrm{O}, \mathrm{RT}, 64 \%$. $^{[14]}$ Diastereoisomer $(S, R)-10$ was not observed in the reaction crude.

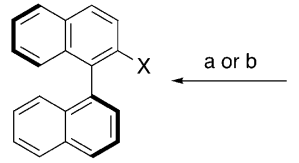

$\mathrm{X}=\mathrm{Br}:\left(R_{\mathrm{a}}\right)-11$

$80 \%$, e.r. $98: 2$

$\mathrm{X}=\mathrm{I}:\left(R_{\mathrm{a}}\right)-12$

$77 \%$, e.r. $98: 2$

Scheme 5. Diversification of the atropisomeric biaryl silane $\left(R_{a}\right)-5 \mathrm{a}$.

a) NBS, $\mathrm{MeCN}, 60^{\circ} \mathrm{C}, 80 \%$; b) ICl, $\mathrm{CH}_{2} \mathrm{Cl}_{2}, \mathrm{RT}, 77 \%$; c) ICl, $n$-heptane, $0{ }^{\circ} \mathrm{C}$, then $p$-tolylzinc chloride, $\mathrm{THF}, \mathrm{Pd}\left(\mathrm{PPh}_{3}\right)_{4}, \mathrm{RT}, 72 \%$. NBS $=$

$\mathrm{N}$-bromosuccinimide.

was achieved by combining a mild iodination with an in situ Negishi cross-coupling ${ }^{[19]}$ using $p$-tolylzinc chloride, thus directly providing the arylated product $\left(R_{a}\right)-\mathbf{1 3}$ in $72 \%$ yield with an e.r. value of 98:2.

In conclusion, a stereochemical relay strategy for the remote central-to-axial chirality conversion was established. Simple aryl esters were converted into axially chiral biaryl silanes with excellent atroposelectivity by using a chiral 1,5bifunctional organomagnesium alkoxide reagent. The remote, encoding stereocenter is readily installed during the synthesis of a highly enantioenriched reagent on large scale. The diastereoselective double addition to esters controls the configuration of the transient stereocenter that guides the central-to-axial chirality conversion upon in situ reduction. Simultaneous planarization of the encoding and transient stereocenter thus results in the formation of a new aromatic ring with up to $98: 2$ enantiocontrol. The scope of this mild reaction comprises axially chiral products with low configurational stability, biaryl phosphines, and anionic substrates, thus providing versatile chiral biaryl carbanion surrogates from ester precursors in one step. Ongoing studies in our group focus on the diastereoselective synthesis of atropisomeric scaffolds with multiple stereogenic axes. 


\section{Acknowledgements}

We gratefully acknowledge the Swiss National Science Foundation (BSSGI0-155902/1), the University of Basel and the NCCR Molecular Systems Engineering for financial support, Dr. M. Neuburger for X-ray crystallography and Priv.-Doz. Dr. D. Häussinger for NMR spectroscopy.

\section{Conflict of interest}

The authors declare no conflict of interest.

Keywords: atropisomerism · biaryls · esters . organomagnesium reagents $\cdot$ stereoselectivity

How to cite: Angew. Chem. Int. Ed. 2018, 57, 7136-7139 Angew. Chem. 2018, 130, 7254-7257

[1] C. Wolf, in Dynamic Stereochemistry of Chiral Compounds: Principles and Applications, The Royal Society of Chemistry, Cambridge, 2008, pp. 233-234 and 257-261.

[2] Selected examples and reviews: a) A. I. Meyers, D. G. Wettlaufer, J. Am. Chem. Soc. 1984, 106, 1135-1136; b) G. Bringmann, A. J. P. Mortimer, P. A. Keller, M. J. Gresser, J. Garner, M Breuning, Angew. Chem. Int. Ed. 2005, 44, 5384-5427; Angew. Chem. 2005, 117, 5518-5563; c) A. Joncour, A. Décor, S. Thoret A. Chiaroni, O. Baudoin, Angew. Chem. Int. Ed. 2006, 45, 4149 4152; Angew. Chem. 2006, 118, 4255-4258; d) O. Baudoin, Eur. J. Org. Chem. 2005, 4223-4229; e) A. Berthelot-Bréhier, A Panossian, F. Colobert, F. R. Leroux, Org. Chem. Front. 2015, 2, 634-644.

[3] Stereospecific reactions controlling a different stereogenic element, while the initial stereogenic unit is "destroyed" in the same step were termed "chirality exchange", "self-immolative" or "chirality conversion". For seminal reports, see: a) J. A Berson, J. Am. Chem. Soc. 1956, 78, 4170; b) Ref. [2a]; c) A Straub, A. Goehrt, Angew. Chem. Int. Ed. Engl. 1996, 35, 2662 2664; Angew. Chem. 1996, 108, 2832-2834; d) T. Hattori, M. Date, K. Sakurai, N. Morohashi, H. Kosugi, S. Miyano, Tetrahedron Lett. 2001, 42, 8035-8038; e) Y. Nishii, K. Wakasugi, K. Koga, Y. Tanabe, J. Am. Chem. Soc. 2004, 126, 5358 5359 ; f) R. W. Baker, G. R. Pocock, M. V. Sargent, Chem. Commun. 1993, 1489-1491; g) Y. Liu, K. Lu, M. Dai, K Wang, W. Wu, J. Chen, J. Quan, Z. Yang, Org. Lett. 2007, 9, $805-$ 808 ; h) F. Guo, L. C. Konkol, R. J. Thomson, J. Am. Chem. Soc. 2011, 133, 18-20; i) L. C. Konkol, F. Guo, A. A. Sarjeant, R. J. Thomson, Angew. Chem. Int. Ed. 2011, 50, 9931 -9934; Angew. Chem. 2011, 123, 10105-10108; j) O. Quinonero, M. Jean, N Vanthuyne, C. Roussel, D. Bonne, T. Constantieux, C. Bressy, X Bugaut, J. Rodriguez, Angew. Chem. Int. Ed. 2016, 55, 1401 1405; Angew. Chem. 2016, 128, 1423-1427; k) O. Quinonero, C. Bressy, X. Bugaut, Angew. Chem. Int. Ed. 2014, 53, $10861-$ 10863; Angew. Chem. 2014, 126, 11039-11041; 1) A. Link, C. Sparr, Chem. Soc. Rev. 2018, DOI: 10.1039/C7CS00875A.

[4] For a desymmetrization approach with remote stereocontrol over axial chirality, see: a) N. Di Iorio, P. Righi, A. Mazzanti, M. Mancinelli, A. Ciogli, G. Bencivenni, J. Am. Chem. Soc. 2014, 136, 10250-10253; for an elegant strategy with 1,2-induction, see: Ref. [3h].

[5] A. Link, C. Fischer, C. Sparr, Angew. Chem. Int. Ed. 2015, 54, 12163-12166; Angew. Chem. 2015, 127, 12331-12334.

[6] a) M. Asami, T. Mukaiyama, Chem. Lett. 1980, 9, 17-20; b) H. Mahler, M. Braun, Tetrahedron Lett. 1987, 28, 5145-5148;
Preorganization by coordination of the alkoxide to the intermediary ketone is consistent with the observed high selectivity. The reversal of selectivity with $\mathbf{1 j}$ was rationalized by alkoxideindolide chelate formation prior to chirality conversion.

[7] a) V. K. Vyas, R. C. Knighton, B. M. Bhanage, M. Wills, Org. Lett. 2018, 20, 975-978; b) M. M. Midland, A. Tramontano, A. Kazubski, R. S. Graham, D. J. S. Tsai, D. B. Cardin, Tetrahedron 1984, 40, 1371-1380.

[8] a) M. Havránek, D. Dvorák, J. Org. Chem. 2002, 67, 2125-2130; b) I. N. Houpis, D. Shilds, U. Nettekoven, A. Schnyder, E. Bappert, K. Weerts, M.

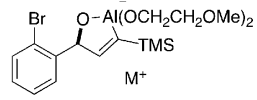
Canters, W. Vermuelen, Org. Process Res. Dev. 2009, 13, 598606.

[9] a) A. Link, C. Fischer, C. Sparr, Synthesis 2017, 49, 397-402.

[10] a) F. M. Piller, P. Appukkuttan, A. Gavryushin, M. Helm, P. Knochel, Angew. Chem. Int. Ed. 2008, 47, 6802-6806; Angew. Chem. 2008, 120, 6907-6911.

[11] See the Supporting Information for details.

[12] S. Okamoto, Chem. Rec. 2016, 16, 857-872.

[13] Conversion percentage $(c p)=e e_{\text {reagent }} / e e_{\text {product }} * 100$, see Ref. [3j].

[14] C-, N-, or P-ortho substitution imparts notable configurational stability $\left(\mathbf{5 a}: \Delta G^{+}{ }_{433 \mathrm{~K}}>135 \mathrm{~kJ} \mathrm{~mol}^{-1}\right)$. CCDC $1820084\left(\left(R_{a}\right)\right.$ 5a), $\left.1820085\left(S_{a}\right)-\mathbf{5}^{\prime} \mathbf{i}\right)$ and $1820086((S, S)-\mathbf{1 0})$ contain the supplementary crystallographic data for this paper. These data can be obtained free of charge from The Cambridge Crystallographic Data Centre.

[15] S. H. Watterson, G. V. De Lucca, Q. Shi, C. M. Langevine, Q. Liu, D. G. Batt, M. Beaudoin Bertrand, H. Gong, J. Dai, S. Yip, P. Li, D. Sun, D.-R. Wu, C. Wang, Y. Zhang, S. C. Traeger, M. A. Pattoli, S. Skala, L. Cheng, M. T. Obermeier, R. Vickery, L. N. Discenza, C. J. D'Arienzo, Y. Zhang, E. Heimrich, K. M. Gillooly, T. L. Taylor, C. Pulicicchio, K. W. McIntyre, M. A. Galella, A. J. Tebben, J. K. Muckelbauer, C. Y. Chang, R. Rampulla, A. Mathur, L. Salter-Cid, J. C. Barrish, P. H. Carter, A. Fura, J. R. Burke, J. A. Tino, J. Med. Chem. 2016, 59, $9173-$ 9200.

[16] a) R. Noyori, H. Takaya, Acc. Chem. Res. 1990, 23, 345-350; b) T. Hayashi, Acc. Chem. Res. 2000, 33, 354-362.

[17] a) K. Yamaguchi, J. Yamaguchi, A. Studer, K. Itami, Chem. Sci. 2012, 3, 2165-2169; b) V. S. Raut, M. Jean, N. Vanthuyne, C. Roussel, T. Constantieux, C. Bressy, X. Bugaut, D. Bonne, J. Rodriguez, J. Am. Chem. Soc. 2017, 139, 2140-2143.

[18] a) P. Somfai, B. Seashore-Ludlow in Organosilicon Reagents: Vinyl-, Alkynyl-, and Arylsilanes, Comprehensive Organic Synthesis (Eds.: P. Knochel, G. A. Molander), Vol. 1 (Ed.: J. Johnson), Elsevier, Oxford, 2014, pp. 27-47; b) S. Bähr, M. Oestreich, Angew. Chem. Int. Ed. 2017, 56, 52-59; Angew. Chem. 2017, 129, 52-59; c) A. A. Toutov, W.-B. Liu, K. N. Betz, B. M. Stoltz, R. H. Grubbs, Nat. Protoc. 2015, 10, 1897-1903; d) L. T. Ball, G. C. Lloyd-Jones, C. A. Russell, Science 2012, 337 , 1644-1648; e) W. E. Brenzovich, Jr., J.-F. Brazeau, F. D. Toste, Org. Lett. 2010, 12, 4728-4731; f) E. Hupe, M. I. Calaza, P. Knochel, Chem. Commun. 2002, 1390-1391; g) Z. Zhao, V. Snieckus, Org. Lett. 2005, 7, 2523-2526; h) K. Gondo, J. Oyamada, T. Kitamura, Org. Lett. 2015, 17, 4778-4781.

[19] a) C. Zarate, R. Martin, J. Am. Chem. Soc. 2014, 136, 22362239 ; b) S. Price, R. Heald, W. Lee, M. E. Zak, J. F. M. Witt, WO2009/085983; c) K. Krascsenicsová, P. Walla, P. Kasák, G. Uray, C. O. Kappe, M. Putala, Chem. Commun. 2004, 26062607.

Manuscript received: March 22, 2018

Version of record online: May 16, 2018 